\title{
Which patients respond best to hepatitis $B$ vaccination after a hepatitis B virus-related liver transplantation?
}

\author{
Akinobu Takaki $\cdot$ Takahito Yagi $\cdot$ Tetsuya Yasunaka $\cdot$ Hiroshi Sadamori $\cdot$ Susumu Shinoura $\cdot$ Yuzo Umeda \\ Ryuichi Yoshida $\cdot$ Daisuke Sato $\cdot$ Daisuke Nobuoka Masashi Utsumi · Yuko Yasuda • Eiichi Nakayama • \\ Yasuhiro Miyake $\cdot$ Fusao Ikeda $\cdot$ Hidenori Shiraha $\cdot$ Kazuhiro Nouso $\cdot$ Toshiyoshi Fujiwara $\cdot$ Kazuhide Yamamoto
}

Received: 31 August 2012/Accepted: 31 January 2013/Published online: 23 February 2013

(C) The Author(s) 2013. This article is published with open access at Springerlink.com

\begin{abstract}
Background A combination of hepatitis B immunoglobulin and nucleos(t)ide analogues is the current standard of care for controlling hepatitis B recurrence after orthotopic liver transplantation (OLT). However, frequent immunoglobulin treatment is expensive and inconvenient. This study investigated the efficacy of hepatitis B virus (HBV) vaccination in preventing the recurrence of hepatitis $B$ after living donor OLT.

Methods Twenty-seven patients who had undergone living donor OLT participated in the study; five had acute HBV infected liver failure (ALF-OLT) and 22 had HBV related liver cirrhosis (LC-OLT). Hepatitis B surface antigen (HBsAg)-containing vaccine was administered to them for at least 1 year after transplantation and continued
\end{abstract}

A. Takaki $(\bowtie) \cdot$ T. Yasunaka $\cdot$ Y. Miyake $\cdot$ F. Ikeda .

H. Shiraha $\cdot$ K. Nouso $\cdot$ K. Yamamoto

Department of Gastroenterology and Hepatology,

Okayama University Graduate School of Medicine,

Dentistry and Pharmaceutical Sciences, 2-5-1 Shikata-cho,

Kita-ku, Okayama 700-8558, Japan

e-mail: akitaka@md.okayama-u.ac.jp

T. Yagi · H. Sadamori - S. Shinoura $\cdot$ Y. Umeda $\cdot$ R. Yoshida

D. Sato · D. Nobuoka $\cdot$ M. Utsumi - T. Fujiwara

Department of Gastroenterological Surgery Transplant

and Surgical Oncology, Okayama University Graduate

School of Medicine, Dentistry and Pharmaceutical Sciences,

2-5-1 Shikata-cho, Kita-ku, Okayama 700-8558, Japan

Y. Yasuda

Okayama University Hospital, 2-5-1 Shikata-cho, Kita-Ku,

Okayama 700-8558, Japan

E. Nakayama

Kawasaki University of Medical Welfare, 288 Matsushima,

Kurashiki, Okayama 701-0193, Japan once monthly for up to 36 months post-OLT. Patients who had anti-HBs antibody titers above $100 \mathrm{mIU} / \mathrm{mL}$ for a minimum of 6 months without immunoglobulin administration were defined as good responders; the others were defined as poor responders. Interferon- $\gamma$ enzyme-linked immunospot assays against $\mathrm{HBs}$ and $\mathrm{HBc}$ antigens were used to assay cellular immune responses.

Results All five of the ALF-OLT patients had good responses after a median of four (range 2.5-5) vaccinations. Nine of the 22 LC-OLT patients had good responses after a median of 19 (range 11.5-30) vaccinations. Among the LC-OLT group, those with livers donated by relatively higher-aged, marital and high-titer anti-HBs antibody donors were good responders. LC-OLT patients classed as good responders showed interferon- $\gamma$ responses comparable to those of the ALF-OLT patients.

Conclusions The ALF-OLT and LC-OLT patients who received livers from relatively higher-aged, marital, high-titer anti-HBs antibody donors were the best candidates for HBV vaccine administration. Boosting donors before transplantation may facilitate later vaccine response of the recipients.

Keywords Vaccination - Living donor liver transplantation - Hepatitis B immunoglobulin - Marital donor - Immune response

\section{Introduction}

Prior to the introduction of effective post-transplantation antiviral prophylaxis, liver transplantation for hepatitis B virus (HBV)-related disease was usually followed by immediate HBV reinfection of the allograft, resulting in a fatal hepatitis B recurrence [1-3]. Recent studies have found that treatment with a combination of hepatitis $\mathrm{B}$ 
immunoglobulin (HBIg) and nucleos(t)ide analogues decreases the risk of hepatitis B recurrence, and achieves a higher rate of graft survival [4-8]. However, long-term administration of HBIg is associated with several unresolved issues, including limited availability and extremely high cost, so several protocols for treatment with low-dose HBIg in combination with nucleos(t)ide analogue have been reported [9-12]. Previously, we reported that treatment with high-dose HBIg in the early period post-transplantation followed by low-dose HBIg with nucleos(t)ide analogues offers reliable, cost-effective control of hepatitis B recurrence [13]. However, even with such a simplified protocol, patients would still need to receive a drip infusion or intramuscular injection of hundreds to thousands of units of HBIg every 2-3 months.

Active immunization of post-orthotopic liver transplantation (OLT) recipients with HBV vaccine is a recently emerging approach. However, most studies report low response rates, even with double concentration of vaccines or prolonged vaccination regimens [14, 15]. Patients who had not been HBV carriers [e.g., acute liver failure (ALF) patients following sexual transmission of $\mathrm{HBV}$ as an adult; or non-chronic HBV carrier patients who received hepatitis $\mathrm{B}$ core antibody ( $\mathrm{HBcAb}$ )-positive livers] are accepted as good candidates for vaccine administration $[15,16]$. Vaccination in patients who have been HBV carriers or liver cirrhosis (LC) patients typically yields disappointing results $[14,15]$. Understanding how different cohorts respond to $\mathrm{HBV}$ vaccination is critical to the design of safe, cost-saving, and custom-designed prophylaxis protocols.

It remains unclear to what extent cellular immune responses may contribute to protection from HBV reinfection. Since non-carrier patients respond well to the HBV vaccination, immune tolerance is expected to play a large role in this process. Yet only a few reports have mentioned $\mathrm{T}$ cell immune reaction after HBV-related OLT [14].

In this report, we assessed a monthly, long-term vaccination protocol starting 1 year after OLT, to investigate those characteristics that could discriminate between the vaccine-responsive and non-responsive patients. In addition to anti-hepatitis B surface (anti-HBs) antibody titer due to a humoral immune response, CD4 $\mathrm{T}$ cell immune responses to hepatitis B surface antigen ( $\mathrm{HBsAg}$ ) were used to assess the cellular immune response to vaccination in immunocompetent patients.

\section{Methods}

Patients

From October 1996 to June 2011, OLT was performed in 264 adults at Okayama University Hospital. Of these, ten patients had ALF due to acute HBV infection. Thirty-seven patients had end-stage LC due to chronic life-long HBV infection. Five-year survival rates were 88 and $87 \%$ for HBV-related ALF patients and for HBV-related LC patients, respectively.

The HBV vaccine was administered to five ALF patients (ALF-OLT) and $22 \mathrm{LC}$ patients (LC-OLT). The general characteristics of the patients included in this study are summarized in Table 1. All of them received living donor liver transplantation (LDLT). The numerical data are expressed as median and interquartile range values, and categorical data are presented as positive counts or percentages in all tables.

For analysis of the HBV-specific cellular immune response (Table 2), the study enrolled all five ALF-OLT patients, along with 15 of the 22 LC-OLT patients. Additionally, 11 healthy volunteers who had received the HBV vaccine and developed a successful anti-HBs antibody response (termed 'Healthy vaccine'), ten patients with chronic hepatitis B (termed 'Chronic hepatitis'), and five patients who recovered from acute hepatitis B (termed 'Self-limited') were enrolled as controls. The five patients who recovered from acute hepatitis B had a history of acute hepatitis B diagnosed with high-titer IgM-HBc antibody response, and presented as HBsAg negative, anti-HBs antibody positive, anti-HBc antibody positive at the time of

Table 1 Patient characteristics

\begin{tabular}{lll}
\hline$N$ & ALF & LC \\
& 5 & 22 \\
\hline Recipient related factors & & \\
Age at OLT & $29(27-46)$ & $53(47-56)$ \\
Age at start of vaccine & $36(30-51)$ & $56(49-59)$ \\
Sex (M) & $1(20 \%)$ & $19(86 \%)$ \\
HBsAg at OLT & $0.7(0-1)$ & $2000(100-2000)$ \\
HBV DNA at OLT $(\geq 3.7)$ & $0(0 \%)$ & $8(36 \%)$ \\
MELD at OLT & $21[19-21]$ & $15[9-18]$ \\
HCC at OLT $(+)$ & $0(0 \%)$ & $15(68 \%)$ \\
Donor related factors & & \\
Age at OLT & $32(27-44)$ & $46(31-49)$ \\
Sex (M) & $4(80 \%)$ & $9(40 \%)$ \\
ABO (identical) & $4(80 \%)$ & $12(54 \%)$ \\
Blood relation (no) & $0(0 \%)$ & $8(36 \%)$ \\
Anti-HBs antibody $(>100)$ & $1(20 \%)$ & $9(40 \%)$ \\
Anti-HBc antibody $(+)$ & $1(20 \%)$ & $11(50 \%)$ \\
Anti-HBc(+)/anti-HBs $(+)$ & $1(20 \%)$ & $10(45 \%)$ \\
Anti-HBc(+)/anti-HBs $(-)$ & $0(0 \%)$ & $1(4 \%)$ \\
Anti-HBc(-)/anti-HBs $(+)$ & $0(0 \%)$ & $0(0 \%)$ \\
\hline
\end{tabular}

$A L F$ acute liver failure, $L C$ liver cirrhosis, $O L T$ orthotopic liver transplantation, MELD Model for End-stage Liver Disease, HCC hepatocellular carcinoma 
Table 2 Characteristics of the cases for HBV antigen-specific T cell response

\begin{tabular}{|c|c|c|c|c|c|c|}
\hline$N$ & $\begin{array}{l}\text { Healthy } \\
\text { vaccine } \\
11\end{array}$ & 10 & 5 & 4 & 8 & $\begin{array}{l}\text { LC-OLT-poor } \\
7\end{array}$ \\
\hline Age & $29(28-31)$ & $53(42.5-61)$ & $67(58.5-77)$ & $41.5(37.2-47.2)$ & $60(53-62)$ & $55(40-58)$ \\
\hline $\operatorname{Sex}[M(\%)]$ & $10(91)$ & $7(70)$ & $2(40)$ & $0(0)$ & $8(100)$ & $7(100)$ \\
\hline HBs Ag (+) & 0 & $\begin{array}{l}10 \text { [titer } 2000 \\
(1893-2000)]\end{array}$ & 0 & 0 & 0 & 0 \\
\hline HBs Ab (IU/l) $(>100 / \leq 100)$ & $8 / 3$ & $0 / 10$ & $2 / 3$ & $2 / 2$ & $4 / 4$ & $1 / 6$ \\
\hline
\end{tabular}

LC-OLT-poor patients received HBIG within 3 months

Age and HBsAg were shown as median (interquartile range)

$A L F$-OLT acute liver failure patients who received OLT, LC-OLT-good liver cirhosis patients who received OLT and had a good vaccine response, $L C$-OLT-poor liver cirrhosis patients who received OLT and had a poor vaccine response

the study. The chronic hepatitis B patients were followed for several years at our hospital and all were $\mathrm{HBsAg}$ positive with a median HBV-DNA titer of 2.5 (interquartile range 2.1-4.2) $\log$ copies/mL. The healthy volunteers had no HBsAg and anti-HBc antibodies, and the median antiHBs antibody level was 240 (interquartile range 100-797) $\mathrm{mIU} / \mathrm{mL}$.

Informed consent was obtained from each patient included in the study, and the study protocol conformed to the ethical guidelines of the 1975 Declaration of Helsinki, as reflected in the approval by the Ethics Committee at the Okayama University Hospital.

\section{Antiviral prophylaxis}

Our HBV prophylaxis protocol was as follows. We administered HBIg at $200 \mathrm{IU} / \mathrm{kg}$ intraoperatively. Recipients were administered another 2000 IU/week HBIg for an additional 1 week post-operatively. HBIg (2000 IU) was administered thereafter only when anti-HBs antibody titers fell below $100 \mathrm{mIU} / \mathrm{mL}$. After 6 months, HBIg was administered only to maintain anti-HBs antibody titers at $>10 \mathrm{mIU} / \mathrm{mL}$. We measured levels of HBsAg and antiHBs antibody and/or HBV-DNA every month for 6 months after LDLT, and every 2-3 months thereafter. Three of the ALF-OLT patients were anti-HBs antibody positive at the time of OLT, these patients were not administered nucleos(t)ide analogues. The remaining two ALF-OLT patients, and all of the LC patients were given nucleos(t)ide analogues. The two ALF-OLT patients were given lamivudine (LAM), and of the 22 LC-OLT patients, 14 received LAM, six were given LAM + adefovir dipivoxyl (ADV), and two received entecavir (ETV). Administration of nucleos(t)ide analogues was started a minimum of 1 month pre-operatively, when possible.

Post-OLT re-activation of $\mathrm{HBV}$ was defined as continuous positivity for serum $\mathrm{HBsAg}$ and/or serum $\mathrm{HBV}$ DNA.
HBV vaccine protocol

HBV vaccine administration was initiated at least 1 year after OLT, and when patients showed no active infection or rejection episode in the preceding month. The vaccine consisted of recombinant purified HBsAg (Bimmugen; Kaketsuken, Kumamoto, Japan). Ten micrograms were administered every 1-2 months. Based on the effect of the vaccine, patients were classified as "good responders; LC-OLT good" or "poor responders; LC-OLT poor". Patients who showed anti-HBs antibody titers above $100 \mathrm{mIU} / \mathrm{mL}$ without HBIg for a minimum of 6 months were defined as good responders, since all of these patients did not need HBIg administration for an additional 2 years (median) of follow-up. All other patients were defined as poor responders. Patients who showed a good response within 36 months were given additional vaccinations when their anti-HBs antibody titer decreased, whereas vaccination was stopped in patients who showed no good response after 36 months.

Immune suppression

Patients were treated using a standard immunosuppressive regimen (tacrolimus or cyclosporine $\mathrm{A}$ with steroids and/or mycophenolate mofetil). One patient was free from calcineurin inhibitors at the time of vaccine administration.

Routine laboratory tests and serum HBV-DNA assay

Hepatitis B surface antigen, anti-HBs antibody, hepatitis Be antigen ( $\mathrm{HBeAg})$, and anti-HBe antibody (HBeAb) levels were measured routinely using a commercially available chemiluminescent enzyme immunoassay system (Lumipulse System; Fujirebio, Tokyo, Japan). HBV-DNA levels were measured using a transcription-mediated amplification assay (TMA) (SRL, Tokyo, Japan), a polymerase chain reaction (PCR) assay (Amplicor HBV 
Monitor assay; Roche Diagnostics, Tokyo, Japan), or a real-time PCR assay (COBAS TaqMan HBV Test; Roche Diagnostics).

HBV recombinant proteins for cellular immune response analysis

Hepatitis B virus recombinant protein $\mathrm{HBsAg}$ was purchased from Advanced ImmunoChemical, Inc. (Long Beach, CA). Recombinant protein hepatitis B core antigen ( $\mathrm{HBcAg}$ ) was purchased from the Institute of Immunology (Tokyo, Japan). These proteins were used as stimulating antigens at $1 \mu \mathrm{g} / \mathrm{mL}$ for the enzyme-linked immunospot (ELISPOT) assay.

CD14-positive monocyte isolation and myeloid DC generation

Mononuclear cells were separated from peripheral blood by centrifugation on the Ficoll-Hypaque density gradient (Amersham Pharmacia, Uppsala, Sweden), as previously described. CD14-positive monocytes were purified using microbeads (Miltenyi Biotec, Auburn, CA) in accordance with the protocols of the manufacturer. Subsequently, CD4-positive $\mathrm{T}$ cells (T4) were positively sorted in the same way. T4 cells were frozen immediately. CD14-positive cells were cultured at $1 \times 10^{6} / \mathrm{mL}$ in RPMI containing $5 \%$ heat-inactivated human $\mathrm{AB}$ serum (ICN Biomedicals; Aurora, $\mathrm{OH}$ ) supplemented with $100 \mathrm{ng} / \mathrm{mL}$ of granulocyte macrophage colony-stimulating factor (kindly provided by Kirin Pharma, Tokyo, Japan) and $50 \mathrm{ng} / \mathrm{mL}$ of interleukin4 (kindly provided by Ono Pharmaceuticals, Osaka, Japan) at $37{ }^{\circ} \mathrm{C}$ in $5 \% \mathrm{CO}_{2}$ for 5 days. Cells were confirmed to be CD11c-positive myeloid immature dendritic cells (DC).

Interferon- $\gamma($ IFN $\gamma)$ ELISPOT assay with myeloid DC and CD4-positive T-cells

The immature DC cultures were exposed to recombinant HBsAg and $\mathrm{HBcAg}(1 \mu \mathrm{g} / \mathrm{mL}$ each) for 1 day. To mature the DCs, $1 \mathrm{ng} / \mathrm{mL}$ of lipopolysaccharide (LPS) (Sigma, St. Louis, MO) was added to the culture 1 day after HBV protein addition. On the same day, mouse anti-human interferon- $\gamma$ antibody (MABTECH, Sweden) was diluted to $5 \mu \mathrm{g} / \mathrm{mL}$ with ELISPOT buffer $\left(0.159 \% \quad \mathrm{Na}_{2} \mathrm{CO}_{3}\right.$, $0.293 \% \mathrm{NaHCO}_{3}$ ) and coated overnight at $4{ }^{\circ} \mathrm{C}$ onto 96-well filtration plates (Millipore, Billerica, MA) at $100 \mu \mathrm{L}$ per well. The coated plate was washed with phosphate-buffered saline (PBS) and blocked with $10 \%$ fetal calf serum in RPMI1640 medium for 1-2 h. Myeloid DCs were counted and seeded at $5 \times 10^{3} /$ well. Cryopreserved T4 cells were thawed, counted, and seeded at $2 \times 10^{5} /$ well. On the next day, the plate was washed six times with PBS. Wells were coated with rabbit anti-interferon- $\gamma$ serum (diluted to $1 / 800$ in PBS), and the plate was incubated at $37{ }^{\circ} \mathrm{C}$ for $2 \mathrm{~h}$. The plate was washed six times with PBS and coated with goat anti-rabbit immunoglobulin G-alkaline phosphatase (IgG-AP; Southern Biotech, Birmingham, AL) diluted to $1 / 2000$ with PBS. After a $1 \mathrm{~h}$ incubation at $37{ }^{\circ} \mathrm{C}$, the plate was washed six times with water and spots were developed using 5-bromo-4-chloro-3indolyl phosphate $p$-toluidine salt and nitroblue tetrazolium chloride (BCIP/NBT) as a substrate. Spot development was stopped after $10 \mathrm{~min}$ by washing with distilled water. The spots were viewed and counted under a microscope.

Statistical analysis

Statistical comparisons were performed using JMP version 9 (SAS Institute, Cary, NC, USA). The Wilcoxon rank-sum test was used to compare the continuous data and the Chisquare test was used to compare categorical data. For multivariate analysis, logistic regression analysis was used. The Steel-Dwass test was used for multiple group analysis. A $p$ value of $<0.05$ was considered significant.

\section{Results}

\section{The effects of HBV vaccination}

None of the patients in the ALF-OLT group showed reactivation of the virus. One patient of the LC-OLT group showed transient positive responses for HBsAg and HBV DNA, however, these became negative again with frequent HBIg administration. At the final observation point, no patients showed HBsAg or HBV DNA-positive response. All five ALF-OLT patients had good responses to vaccination (Table 3). A median of four (range 2.5-5) vaccinations were sufficient to induce a good response. In contrast, LC-OLT patients were less responsive, with only nine of 22 displaying a good response. Additionally, these nine good responders required a median of 19 (range 11.5-30) vaccinations before these patients could be weaned from HBIg administration (Fig. 1).

Table 3 Results of HBV vaccination

\begin{tabular}{|c|c|c|}
\hline$N$ & $\begin{array}{l}\text { ALF } \\
5\end{array}$ & $\begin{array}{l}\mathrm{LC} \\
22\end{array}$ \\
\hline $\begin{array}{l}\text { Response to vaccination } \\
\text { (good/poor responders) }\end{array}$ & $5 / 0$ & $9 / 13$ \\
\hline $\begin{array}{l}\text { Number of vaccinations require } \\
\text { before ceasing HBIg treatment }\end{array}$ & $4(2.5-5)$ & $19(11.5-30)$ \\
\hline
\end{tabular}

HBIg Hepatitis B immunoglobulin 
Vaccine safety

None of the patients showed any adverse reactions as judged by their general condition, or by laboratory examination. One patient reported itchiness after injection of the eighth vaccination dose, although the symptom subsequently stopped.

The characteristics of vaccine responsiveness in LC-OLT patients

To determine the characteristics for defining a good response in LC-OLT patients, clinical data from recipients and donors were investigated (Table 4). The background data of the recipients, including HBV-DNA levels, HBeAg positive reactions, HBsAg levels at the time of OLT, and the anti-HBs antibody titer at the time of the initial vaccination did not differ between the good and poor responder groups (Table 5). However, the donor-related factors did differ. Notably, the good responders' donors were relatively high in age $(p=0.019)$ and not blood relatives of the recipients $(p<0.001)$. These donors (to good responders) showed high anti-HBs antibody titers at the time of OLT $(p=0.038)$. Since all of the patients in this study received LDLT, non-blood-related donors all corresponded to spouses of the OLT recipients. Multivariate logistic regression analysis was carried out with the following variables: donor age at OLT $\geq 47$, non-bloodrelated donor, donor anti-HBs antibody titer $>100 \mathrm{mIU} / \mathrm{mL}$ (Table 6). A status of non-blood-related donor was identified as a significant independent predictor of a good response to vaccination. Since the donor anti-HBs antibody was one of the factors associated with a good response, we asked whether the donors had received vaccination, and found that none of them had ever received an HBV vaccine. As shown in Table 4, none of the donors showed the anti-HBc antibody-negative, anti-HBs antibody-positive condition which indicates vaccine-induced seropositivity to the HBs antigen.

HBV antigen-specific immune responses

To determine the effectiveness of vaccine-induced cellular immune responses in post-OLT patients, we used the IFN- $\gamma$ ELISPOT assay. First of all, we analyzed the clinical characteristics of those patients showing strong HBsAg-specific T cell immune responses when compared with those of non-transplanted patients, and vaccineinduced anti-HBs antibody-positive, healthy volunteers (Fig. 2). The patients with stronger HBsAg-specific CD4 $\mathrm{T}$ cell IFN- $\gamma$ responses (equal or more than the median; 7 spots) showed lower levels of HBV DNA, lower HBsAg, higher anti-HBs antibody titer, and higher $\mathrm{HBcAg}$-specific immune responses. The HBsAg and $\mathrm{HBcAg}$-specific CD4 $\mathrm{T}$ cell immune response under different clinical conditions is shown (Fig. 3). Volunteer controls who were positive for anti-HBs antibodies (as a result of previous vaccine administration) showed numerous $\mathrm{HBsAg}$-specific IFN $\gamma$ spots. Spot numbers were reduced in control chronic hepatitis B patients, but remained high (against both HBsAg and $\mathrm{HBcAg}$ ) in acute resolved hepatitis B patients. The ALF-OLT and LC-OLT good responders had relatively higher $\mathrm{HBsAg}$-specific T-cell immune responses than LC-OLT poor responders. The LC-OLT patients with successful vaccine-induced humoral immune responses also showed higher cellular immune responses than control chronic hepatitis B patients. The LC-OLT patients with poor vaccine responses also had low cellular responses, similar to those seen in chronic hepatitis B patients.

\section{Discussion}

In this study we found that HBV vaccination was effective in OLT patients whose donors were relatively high in age, marital (non-blood-related), with high-titer anti-HBs antibodies. The multivariate analysis revealed that a marital (non-blood-related) donor was the only factor that associated strongly with a good response to vaccine. Among these OLT recipients, a good response to vaccination included effective responses in both the humoral and cellular arms of the immune system.

Controlling HBV reactivation after OLT is critical. In the absence of prophylaxis, hepatitis B recurs very frequently and results in early graft failure. The prophylaxis protocols have progressed from HBIg immunoprophylaxis in the early 1990s, to lamivudine in the late 1990s, to the more recent application of HBIg combined with nucleos(t)ide analogues. In 1991, Muller et al. [17] reported the first use of long-term HBIg immunoprophylaxis, reducing the HBV recurrence rate to $25 \%$ after 6 months of OLT and $18 \%$ after 12 months. A multicenter study revealed that the three-year risk of HBV recurrence was $75 \pm 6 \%$ without HBIg, $74 \pm 5 \%$ with short-term (2-month) HBIg, and $36 \pm 4 \%$ with long-term (>6-month) HBIg treatment [18]. Patients who were positive for HBeAg or HBV-DNA displayed the greatest risk of recurrence $(83 \%)$; patients with acute fulminant liver failure showed the lowest risk $(16 \%)$.

In 1996, Grellier et al. [19] reported a trial of LAM as a prophylactic treatment, achieving $18 \%$ recurrence of HBV at 6 months after OLT. However, the long-term recurrence rate at 3 years after OLT progressed to $41 \%$, indicating that LAM monotherapy is not recommendable for posttransplantation prophylaxis. 
Fig. 1 Individual patients' timecourse of anti-HBs antibody titer after vaccine administration. The timecourse of the anti-HBs antibody titer after the first vaccine administration is shown. The arrowhead indicates a vaccine administration point, and the square head indicates an HBIg administration point. a Patients who received orthotopic liver transplantation (OLT) due to hepatitis B-related acute liver failure (ALF-OLT). All patients had a good response to vaccination. b Patients who received OLT due to liver cirrhosis with a good response to vaccination (LC-OLT good). c LC-OLT patients with a poor response to vaccination (LCOLT poor) (a) ALF-OLT
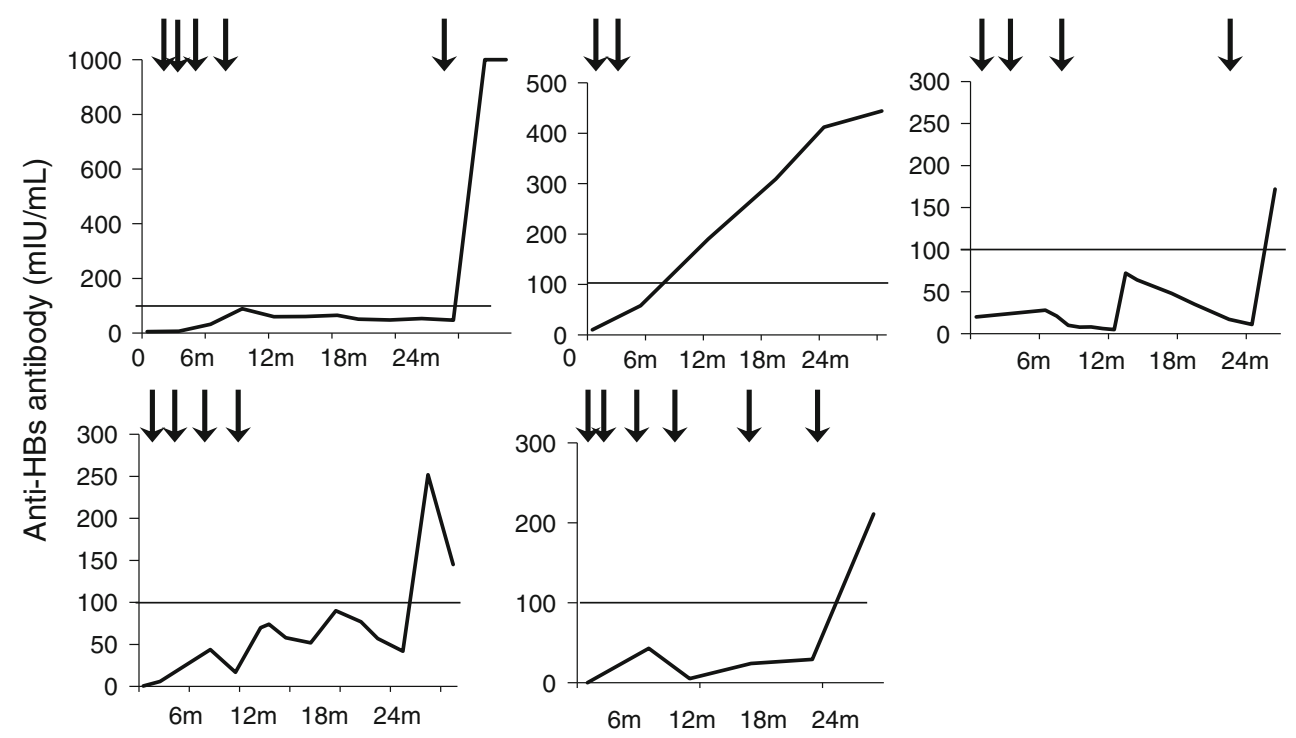

Months after first vaccine administration

(b) LC-OLT good
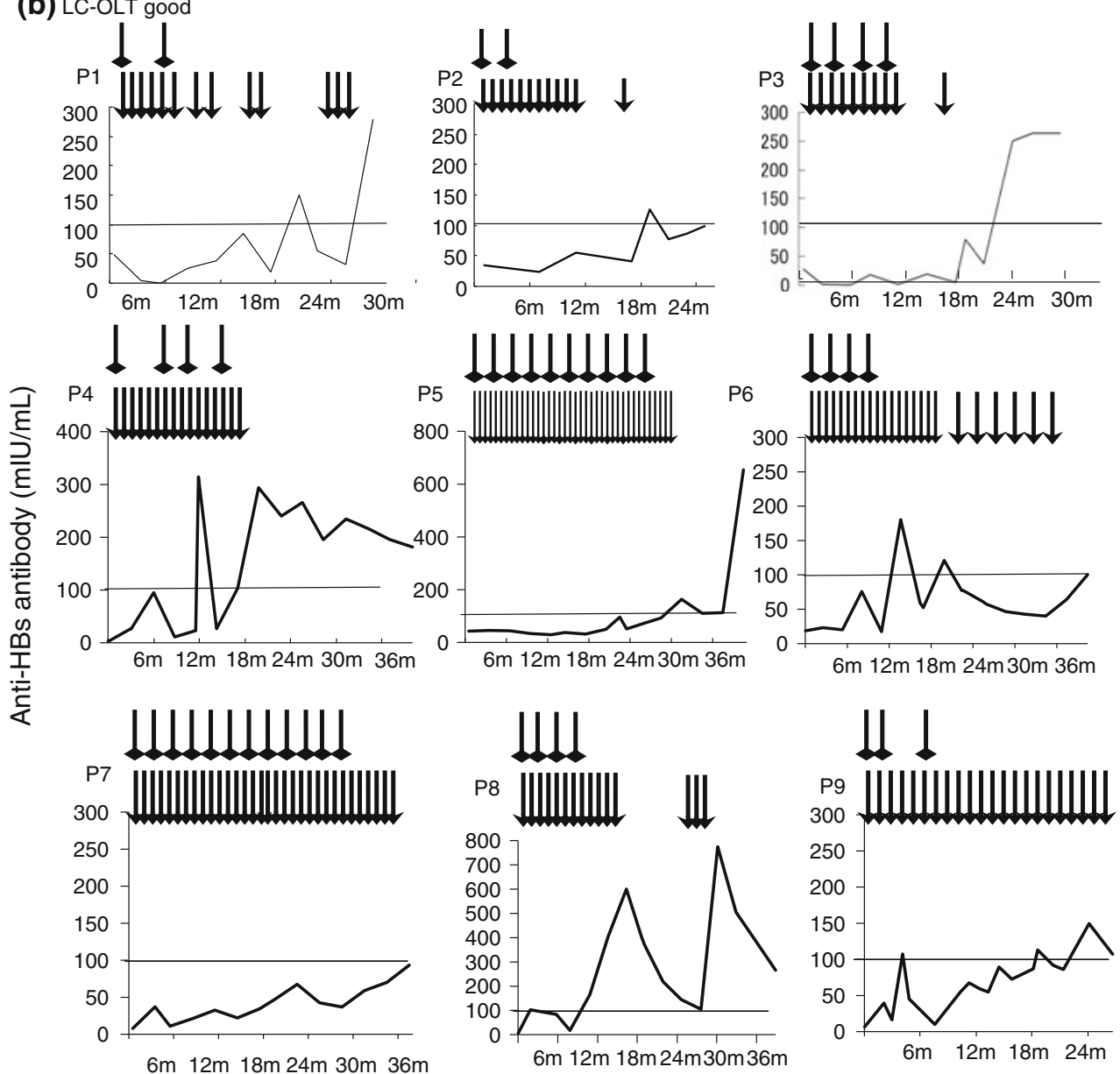

Months after first vaccine administration

Markowitz et al. [20] reported no recurrences after 1 year of combination therapy. Since HBIg is very expensive, several reports have described modified combination 
Fig. 1 continued

(c) LC-OLT poor
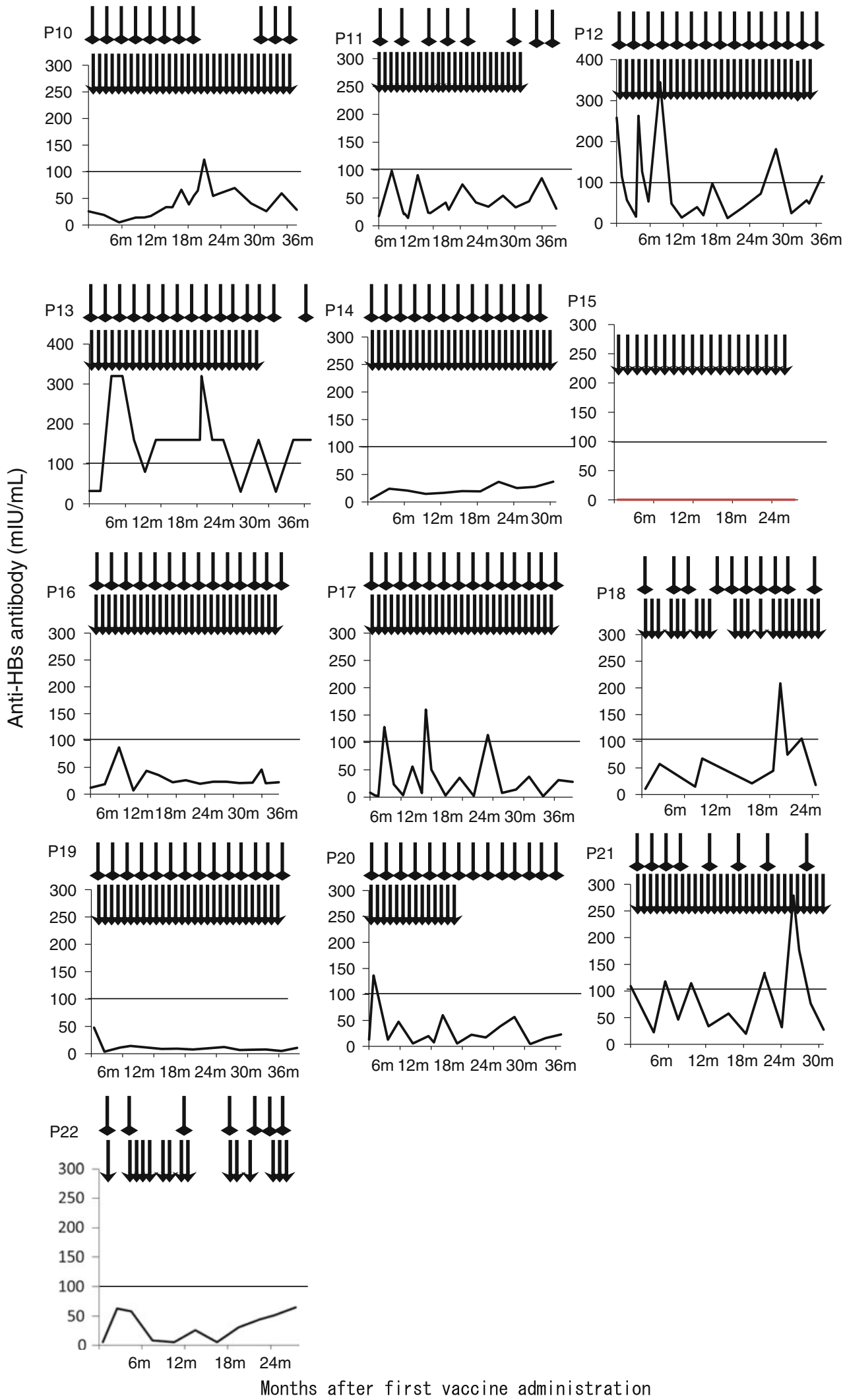


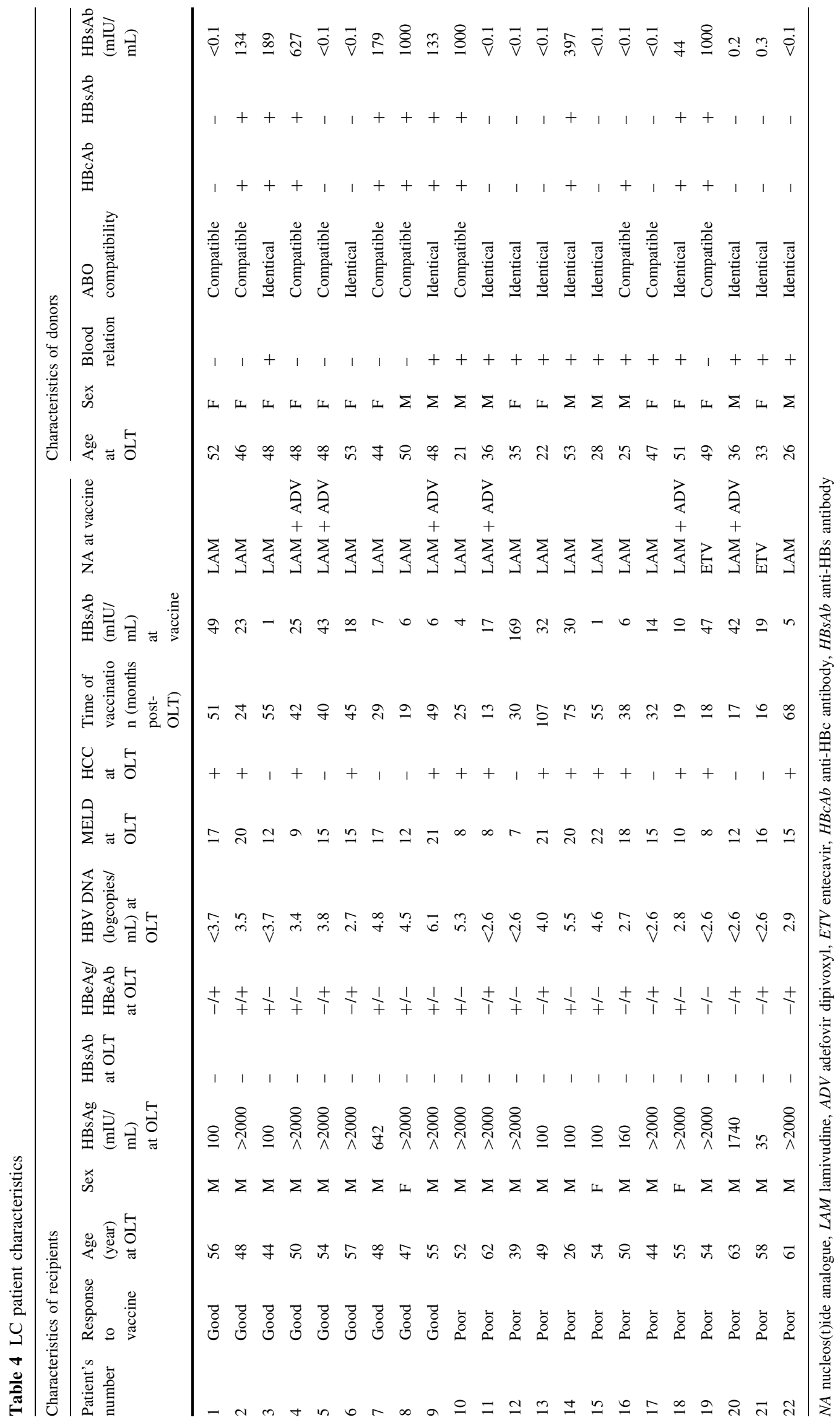


Table 5 Patient characteristics according to vaccine responsiveness in LC (univariate analysis)

\begin{tabular}{|c|c|c|c|}
\hline$N$ & $\begin{array}{l}\text { Good } \\
\text { responders } \\
9\end{array}$ & $\begin{array}{l}\text { Poor } \\
\text { responders } \\
13\end{array}$ & $p$ value \\
\hline \multicolumn{4}{|l|}{ Recipient related factors } \\
\hline Age at OLT & $50(47-55)$ & $54(46-59)$ & 0.546 \\
\hline Sex (male) & $8(88 \%)$ & $11(84 \%)$ & 0.774 \\
\hline $\begin{array}{l}\text { Time of vaccination } \\
\text { (months after OLT) }\end{array}$ & $42(26-50)$ & $30(17-61)$ & 0.442 \\
\hline $\begin{array}{l}\text { HBsAg at OLT } \\
(\geq 1500 \mathrm{IU} / 1)\end{array}$ & $6(66 \%)$ & $8(61 \%)$ & 0.805 \\
\hline $\mathrm{HBeAg}$ positive at OLT & $6(66 \%)$ & $5(38 \%)$ & 0.190 \\
\hline $\begin{array}{l}\text { HBV DNA at OLT }(\geq 3.7 \\
\text { logcopies } / \mathrm{mL})\end{array}$ & $4(44 \%)$ & $4(30 \%)$ & 0.513 \\
\hline MELD at OLT & $15[12-18]$ & $15[8-19]$ & 0.480 \\
\hline Child-Pugh score at OLT & $10[8-10]$ & $9[6-11]$ & 0.845 \\
\hline $\mathrm{HCC}$ at $\mathrm{OLT}(+)$ & $6(66 \%)$ & $9(69 \%)$ & 0.899 \\
\hline $\begin{array}{l}\text { Anti-HBs antibody titer at the } \\
\text { start of vaccination }\end{array}$ & $18.6(6.4-34.6)$ & $17.4(5.9-37.1)$ & 0.920 \\
\hline $\begin{array}{l}\text { Nucleos(t)ide analogue } \\
(\text { LAM/LAM + ADV/ETV) }\end{array}$ & $6 / 3 / 0$ & $8 / 3 / 2$ & 0.312 \\
\hline Tacrolimus/cyclosporinA & $6 / 3$ & $11 / 1 \#$ & 0.148 \\
\hline Tacrolimus level (ng/mL) & $4.7(3.0-5.6)$ & $3.8(2.9-5.8)$ & 0.744 \\
\hline \multicolumn{4}{|l|}{ Donor-related factors } \\
\hline Age at OLT & $48(47-51)$ & $33(25-48)$ & $0.019 *$ \\
\hline $\operatorname{Sex}(M)$ & $2(22 \%)$ & $7(53 \%)$ & 0.138 \\
\hline ABO (identical) & $3(33 \%)$ & $9(69 \%)$ & 0.093 \\
\hline Blood relation (no) & $7(77 \%)$ & $1(7 \%)$ & $<0.001 *$ \\
\hline Anti-HBs antibody titer $(>100)$ & $6(66 \%)$ & $3(23 \%)$ & $0.038 *$ \\
\hline Anti-HBc antibody $(+)$ & $6(66 \%)$ & $5(38 \%)$ & 0.190 \\
\hline Anti-HBc(+)/anti-HBs(+) & $6(66 \%)$ & $4(30 \%)$ & 0.093 \\
\hline $\operatorname{Anti}-\mathrm{HBc}(+) / \operatorname{anti}-\mathrm{HBs}(-)$ & $0(0 \%)$ & $1(7 \%)$ & 0.297 \\
\hline $\operatorname{Anti}-\mathrm{HBc}(-) / \operatorname{anti}-\mathrm{HBs}(+)$ & $0(0 \%)$ & $0(0 \%)$ & - \\
\hline
\end{tabular}

MELD Model for End-stage Liver Disease, HCC hepatocellular carcinoma, LAM lamivudine, $A D V$ adefovir dipivoxyl, ETV entecavir

\# One patient received no calcineurin inhibitor

Table 6 Multiple logistic analysis of factors associated with good responses to $\mathrm{HBV}$ vaccine in $\mathrm{LC}$

\begin{tabular}{lrll}
\hline$N$ & $\begin{array}{c}\text { Odds } \\
\text { ratio }\end{array}$ & $95 \%$ CI & $p$ value \\
\hline Age at OLT $(>47)$ & 5.4 & $0.300-214.000$ & 0.244 \\
Blood relation (no) & 29.4 & $2.551-984.110$ & $0.005^{*}$ \\
Anti-HBs antibody titer & 5.0 & $0.343-149.947$ & 0.233 \\
$\quad(>100)$ & & & \\
\hline
\end{tabular}

Note: Variables significant at $p<0.05$

therapies. We previously have shown that long-term LAM with short-term, high-dose HBIg followed by low-dose HBIg (sufficient to maintain an anti-HBs antibody titer of $>10 \mathrm{mIU} / \mathrm{mL}$ ) is cost-effective and powerful enough to control HBV recurrence after LDLT [13]. With this

\section{HBV-DNA}

(logcopies $/ \mathrm{mL}$ )
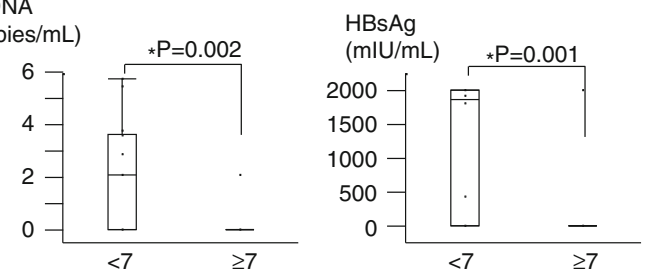

IFN- $\gamma$ SPOT (counts) for HBsAg

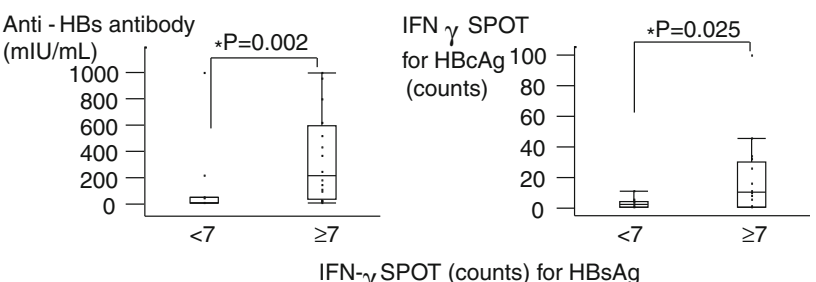

Fig. 2 The clinical characteristics of the non-OLT patients with strong HBsAg-specific $\mathrm{T}$ cell interferon- $\gamma$ response. The clinical characteristics of the non-OLT patients showing strong HBsAgspecific $\mathrm{T}$ cell immune responses by enzyme-linked immunospot (ELISPOT) assay are shown. Those patients with stronger HBsAgspecific CD4 T cell IFN- $\gamma$ response (equal or more than the median; 7 spots) showed lower HBV DNA, lower HBsAg, higher anti-HBs antibody titer, and higher $\mathrm{HBcAg}$-specific immune responses

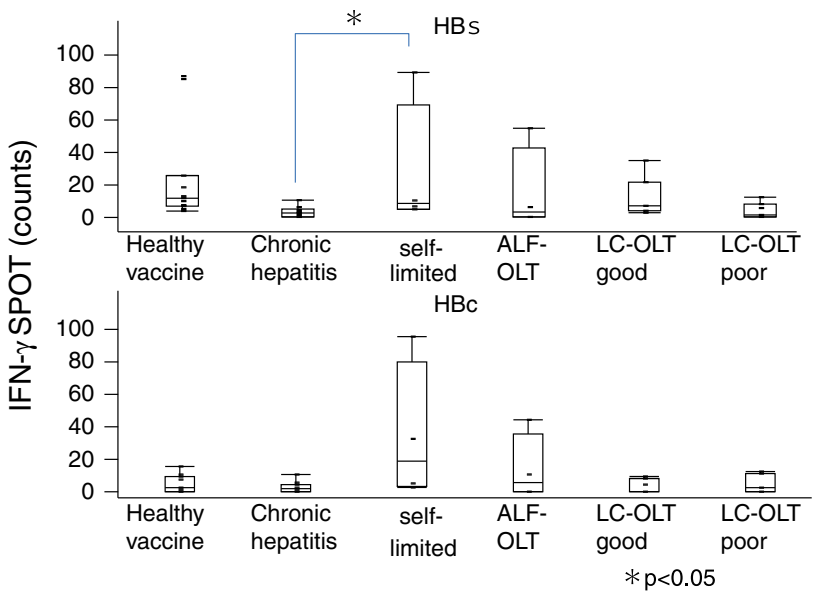

Fig. 3 Cellular immune responses against HBsAg including OLT patients. The number of spots due to interferon- $\gamma$ response in the ELISPOT assay for HBsAg (upper figure) and $\mathrm{HBcAg}$ (lower figure) is shown. 1 Healthy vaccine: healthy controls who were positive for anti-HBs antibodies with HBV vaccine $(n=11) .2$ Chronic hepatitis: chronic hepatitis B patients $(n=10)$. 3 Self-limited: self-limited acute hepatitis B patients who showed serum anti-HBs antibodypositive/HBcAb-positive with no $\mathrm{HBsAg}$ or HBV-DNA $(n=5) .4$ ALF-OLT: post-OLT acute liver failure patients $(n=4) .5$ LC-OLT good: post-OLT liver cirrhosis patients who showed good response to vaccine $(n=8)$. 6 LC-OLT poor: post-OLT liver cirrhosis patients who showed poor response to vaccine $(n=7)$. Values are plotted as median (range)

cost-saving method, no clinical evidence of HBV recurrence has been seen.

In 2000, Sanchez-Fueyo et al. [21] reported an $82 \%$ response to HBV vaccination after OLT. These researchers 
used three cycles of double-dose recombinant HBsAg vaccine for immunization over 6 months, with a target antibody titer of $>10 \mathrm{mIU} / \mathrm{mL}$. The cohort included six acute infected patients and 11 chronic carriers. However, recent reports show that chronic HBV carrier recipients did not respond well, with response rates ranging from 7.7 to $12.5 \%$ [22, 23]. Acute HBV-infected patients who underwent OLT were often positive for the anti-HBs antibody even before OLT, with strong immune responses. Such patients might be expected to respond well to vaccination, since these individuals (unlike chronic carriers) have not developed a tolerance to HBV. In our patients, five acute infected patients showed good responses to vaccination, responding after a median of only four vaccinations. These results indicate that while acute HBVinfected patients are good candidates for HBV vaccination post-OLT; chronic HBV carriers are poorer candidates for this protocol. However, as some HBV carriers did respond to vaccination; further studies should be performed to clarify the differences between the good and poor responders.

Several reports have identified the differences between good responders and poor responders in non-HBV-infected patients who received $\mathrm{HBcAb}$-positive donor livers. Lacking previous HBV exposure, these recipients should not have developed tolerance to the virus and so should have been good responders. Of these, good responses were seen in pediatric cases where the recipients had higher antiHBs antibody titers at the time of OLT and lower tacrolimus levels at the time of vaccination [24]. The present study revealed that repeated vaccine administration resulted in successful immunization in $40 \%$ of the LC-OLT recipients. For these recipients, the strength of the response did not correlate with recipient characteristics, not even with age, one of the most important factors for successful immunization [25]. In contrast, the characteristics of the donor were important. The good responders' donors were relatively high in age, non-blood-related and had high antiHBs antibody titers before donation. Note that, in our trial, the term "non-blood-related donor" indicates the spouse of the recipient, since deceased donor liver transplantation is not widely accepted in Japan [26]. The donors with hightiter anti-HBs antibody probably were infected with HBV by the recipients after their marriage, resulting in the antiHBs antibody boost. These donors' immune systems should not have developed tolerance to the virus. This elevated immunity might be the reason why our patients had relatively better outcomes following vaccination than those of previous reports [27]. Adoptive immune transfer of HBV-specific immune response could be possible [28]. For successful transfer of immune memory to the recipients, the anti-HBs antibody titer of the donors should be high, and vaccine-induced anti-HBs antibody might be less effective than antibodies produced in a previous self-limited infection. Luo et al. [29] have shown that a particularly high anti-HBs antibody titer ( $>1000 \mathrm{IU} / \mathrm{L})$ in the donor is essential for adoptive immune transfer. The results of the present study suggest that HBV vaccination of non-bloodrelated living donor candidates having a lower anti-HBs antibody titer $(<100 \mathrm{mIU} / \mathrm{mL})$ might facilitate improved vaccine response post-OLT in LC recipients.

The present study of HBV vaccine efficacy in ALF-OLT and LC-OLT patients revealed that the vaccine response depended on the immune tolerance to the virus in both recipients and donors. The liver is the biggest immune organ in the abdomen and so can play a critical role in immune responses. Multiple populations of non-hematopoietic liver cells, including sinusoidal endothelial cells, stellate cells located in the subendothelial space, and liver parenchymal cells, take on the roles of antigen-presenting cells [30]. The viral-specific immune competence of the grafted liver might overcome the general immunotolerance to the virus in chronic HBV carriers.

In conclusion, patients who received OLT due to acute infection of HBV were good candidates for HBV vaccination. The chronic HBV carrier recipients who received livers from donors who were non-blood-related (i.e, the recipient's spouse) and who harbored high anti-HBs antibody titers were the best candidates for HBV vaccine administration. Vaccine-induced, HBV-specific immune responses were strong enough to induce not only humoral but also cellular responses in vitro.

Acknowledgments We thank Taiko Kameyama, Asuka Maeda, Chizuru Mori, and Mayumi Honda for carrying out the ELISPOT assay experiments at our institute. Toshie Ishii assisted in the collection of the clinical data and assembly of the data files.

Conflict of interest The authors declare that they have no conflict of interest.

Open Access This article is distributed under the terms of the Creative Commons Attribution Noncommercial License which permits any noncommercial use, distribution, and reproduction in any medium, provided the original author(s) and the source are credited.

\section{References}

1. Todo S, Demetris AJ, Van Thiel D, Teperman L, Fung JJ, Starzl TE. Orthotopic liver transplantation for patients with hepatitis B virus-related liver disease. Hepatology. 1991;13(4):619-26.

2. Davies SE, Portmann BC, O'Grady JG, Aldis PM, Chaggar K, Alexander GJ, et al. Hepatic histological findings after transplantation for chronic hepatitis B virus infection, including a unique pattern of fibrosing cholestatic hepatitis. Hepatology. 1991;13(1):150-7.

3. O'Grady JG, Smith HM, Davies SE, Daniels HM, Donaldson PT, Tan KC, et al. Hepatitis B virus reinfection after orthotopic liver 
transplantation. Serological and clinical implications. J Hepatol. 1992;14(1):104-11.

4. Bartholomew MM, Jansen RW, Jeffers LJ, Reddy KR, Johnson $\mathrm{LC}$, Bunzendahl $\mathrm{H}$, et al. Hepatitis-B-virus resistance to lamivudine given for recurrent infection after orthotopic liver transplantation. Lancet. 1997;349(9044):20-2.

5. Fontana RJ, Hann HW, Wright T, Everson G, Baker A, Schiff ER, et al. A multicenter study of lamivudine treatment in 33 patients with hepatitis B after liver transplantation. Liver Transpl. 2001;7(6):504-10.

6. Papatheodoridis GV, Sevastianos V, Burroughs AK. Prevention of and treatment for hepatitis B virus infection after liver transplantation in the nucleoside analogues era. Am J Transplant. 2003;3(3):250-8.

7. Yoshida H, Kato T, Levi DM, Regev A, Madariaga JR, Nishida $\mathrm{S}$, et al. Lamivudine monoprophylaxis for liver transplant recipients with non-replicating hepatitis B virus infection. Clin Transplant. 2007;21(2):166-71.

8. Ferretti G, Merli M, Ginanni Corradini S, Callejon V, Tanzilli P, Masini A, et al. Low-dose intramuscular hepatitis B immune globulin and lamivudine for long-term prophylaxis of hepatitis B recurrence after liver transplantation. Transplant Proc. 2004; 36(3):535-8.

9. Roche B, Samuel D. Evolving strategies to prevent HBV recurrence. Liver Transpl. 2004;10(10 Suppl 2):S74-85.

10. Buti M, Mas A, Prieto M, Casafont F, Gonzalez A, Miras M, et al. A randomized study comparing lamivudine monotherapy after a short course of hepatitis B immune globulin (HBIg) and lamivudine with long-term lamivudine plus HBIg in the prevention of hepatitis B virus recurrence after liver transplantation. J Hepatol. 2003;38(6):811-7.

11. Di Paolo D, Tisone G, Piccolo P, Lenci I, Zazza S, Angelico M. Low-dose hepatitis B immunoglobulin given "on demand" in combination with lamivudine: a highly cost-effective approach to prevent recurrent hepatitis B virus infection in the long-term follow-up after liver transplantation. Transplantation. 2004;77(8): 1203-8.

12. Karasu Z, Ozacar T, Akyildiz M, Demirbas T, Arikan C, Kobat A, et al. Low-dose hepatitis B immune globulin and higher-dose lamivudine combination to prevent hepatitis $\mathrm{B}$ virus recurrence after liver transplantation. Antivir Ther. 2004;9(6):921-7.

13. Takaki A, Yagi T, Iwasaki $Y$, Sadamori $H$, Matsukawa $H$, Matsuda H, et al. Short-term high-dose followed by long-term low-dose hepatitis B immunoglobulin and lamivudine therapy prevented recurrent hepatitis B after liver transplantation. Transplantation. 2007;83(2):231-3.

14. Rosenau J, Hooman N, Rifai K, Solga T, Tillmann HL, Grzegowski E, et al. Hepatitis B virus immunization with an adjuvant containing vaccine after liver transplantation for hepatitis B-related disease: failure of humoral and cellular immune response. Transpl Int. 2006;19(10):828-33.

15. Ishigami M, Kamei H, Nakamura T, Katano Y, Ando H, Kiuchi $T$, et al. Different effect of HBV vaccine after liver transplantation between chronic HBV carriers and non-HBV patients who received HBcAb-positive grafts. J Gastroenterol. 2011;46(3):367-77.

16. Zhang J, Zhou L, Zheng SS. Clinical management of hepatitis B virus infection correlated with liver transplantation. Hepatobiliary Pancreat Dis Int. 2010;9(1):15-21.

17. Muller R, Gubernatis G, Farle M, Niehoff G, Klein H, Wittekind $\mathrm{C}$, et al. Liver transplantation in HBs antigen (HBsAg) carriers. Prevention of hepatitis B virus (HBV) recurrence by passive immunization. J Hepatol. 1991;13(1):90-6.

18. Samuel D, Muller R, Alexander G, Fassati L, Ducot B, Benhamou JP, et al. Liver transplantation in European patients with the hepatitis B surface antigen. N Engl J Med. 1993;329(25):1842-7.

19. Grellier L, Mutimer D, Ahmed M, Brown D, Burroughs AK, Rolles $\mathrm{K}$, et al. Lamivudine prophylaxis against reinfection in liver transplantation for hepatitis B cirrhosis. Lancet. 1996; 348(9036):1212-5.

20. Markowitz JS, Martin P, Conrad AJ, Markmann JF, Seu P, Yersiz $\mathrm{H}$, et al. Prophylaxis against hepatitis $\mathrm{B}$ recurrence following liver transplantation using combination lamivudine and hepatitis B immune globulin. Hepatology. 1998;28(2):585-9.

21. Sanchez-Fueyo A, Rimola A, Grande L, Costa J, Mas A, Navasa $\mathrm{M}$, et al. Hepatitis B immunoglobulin discontinuation followed by hepatitis B virus vaccination: a new strategy in the prophylaxis of hepatitis B virus recurrence after liver transplantation. Hepatology. 2000;31(2):496-501.

22. Rosenau J, Hooman N, Hadem J, Rifai K, Bahr MJ, Philipp G, et al. Failure of hepatitis B vaccination with conventional $\mathrm{HBsAg}$ vaccine in patients with continuous HBIG prophylaxis after liver transplantation. Liver Transpl. 2007;13(3):367-73.

23. Lo CM, Liu CL, Chan SC, Lau GK, Fan ST. Failure of hepatitis B vaccination in patients receiving lamivudine prophylaxis after liver transplantation for chronic hepatitis B. J Hepatol. 2005; 43(2):283-7.

24. Kwon CH, Suh KS, Yi NJ, Chang SH, Cho YB, Cho JY, et al. Long-term protection against hepatitis $\mathrm{B}$ in pediatric liver recipients can be achieved effectively with vaccination after transplantation. Pediatr Transplant. 2006;10(4):479-86.

25. Linton PJ, Dorshkind K. Age-related changes in lymphocyte development and function. Nat Immunol. 2004;5(2):133-9.

26. Yoshimura N, Okajima H, Ushigome H, Sakamoto S, Fujiki M, Okamoto M. Current status of organ transplantation in Japan and worldwide. Surg Today. 2010;40(6):514-25.

27. Wursthorn K, Wedemeyer H, Manns MP. Managing HBV in patients with impaired immunity. Gut. 2010;59(10):1430-45.

28. Schumann A, Lindemann M, Valentin-Gamazo C, Lu M, Elmaagacli A, Dahmen U, et al. Adoptive immune transfer of hepatitis B virus specific immunity from immunized living liver donors to liver recipients. Transplantation. 2009;87(1):103-11.

29. Luo Y, Lo CM, Cheung CK, Lau GK, Fan ST, Wong J. Identification of hepatitis B virus-specific lymphocytes in human liver grafts from HBV-immune donors. Liver Transpl. 2007;13(1):71-9.

30. Crispe IN. The liver as a lymphoid organ. Annu Rev Immunol. 2009;27:147-63. 